\title{
HAULAGE SYSTEM SELECTION FOR PARVADEH COAL MINE USING MULTI-CRITERIA DECISION MAKING METHODS
}

\author{
Mohammad Amin GHASVAREH ${ }^{1}$, Mohsen SAFARI ${ }^{2 *}$, \\ Majid NIKKHAH ${ }^{3}$
}

${ }^{1}$ Masters Student in Mining, Dept. of Mining Engineering, Shahrood University of Technology, Iran, Aminghasvareh@shahroodut.ac.ir

${ }^{2}$ Faculty Member, Department of Mining Engineering, Birjand University of Technology, Birjand, Iran, msafari@birjandut.ac.ir

3 Assistant Professor, Department of Mining Engineering, Shahrood University of Technology, Iran, M.nikkhah@shahroodut.ac.ir

\begin{abstract}
One of the key components of any project, especially mining projects, is the selection and design of haulage equipment. In most mining activities, which sometimes include mining machinery, haulage costs form a major part of the operating expenses as a matter of concern to mine managers. Due to various factors affecting the selection process of a haulage system, it is not considered a crystal clear one. Because of the complexity and multi-criterion characteristic of the selection process, the use of multi-criterion decision-making methods can be of great help to solve this problem. The TOPSIS, AHP and VIKOR methods among the multi-criterion decision-making methods are some options which are based on priority ranking. In the current paper, the loading systems of conveyors, wagons and winches as well as the locomotives and wagons are investigated. Then, the aforementioned systems are used to make a hybrid based on eight criteria, which yields the best loading system for the Parvadeh Coal Mine in Tabas. Since the obtained results were not consistent with each other in some cases, some integration techniques were utilized to employ the above methods. After integrating the results of the ranking methods, the conveyor haulage system was eventually introduced as the best option.
\end{abstract}

Keywords: AHP, haulage system, multi-criteria decision, TOPSIS, VIKOR

* Corresponding author: msafari@birjandut.ac.ir (M. Safari)

doi: $10.37190 / \mathrm{msc} 192606$ 


\section{INTRODUCTION}

Underground mines have changed their operation systems in accordance with the evolution of equipment, systems and methods of mining. Haulage system is also of critical importance in underground mines just as the mining operation itself is. The haulage and extraction of materials are always among the costliest mining activities, so one of the most important economic parameters in a mine to be considered is transport costs, as a determining factor in providing economic or uneconomic mineral reserve. The underground haulage system of ores, materials, equipment and people has been developed from a primitive hand operation to an automated operation through the rapid progress in the technology of equipment production and methods of extraction, leading to higher productivity (Matsui 2001). The equipment selection process begins with the initial conception of mine development. In many industries, the materials handling represents a significant component of the operational costs, making equipment selection a serious challenge to the management.

Since the selection of suitable haulage equipment for a mine depends on many criteria and variables, making decisions in such problems can often be an arduous task. For these reasons, the need for a mechanism capable of assisting the characterization of such complex scenarios arises. In spite of the studies conducted by Bascetin et al. (2006), Aghajani et al. (2007) and Despodov and Peltechki (2011) and Mizrak Özfirat et al. (2017), the lack of a specific formulation for selecting the appropriate haulage equipment is still a problem. Multi-criterion decision making analysis (MCDA) emerged as a branch of the operational research aimed at facilitating the resolution of these issues. Since then, a great variety of multi-criterion decision making methods (MCDM) have been developed to tackle them under different circumstances and fields of application (Karahalios et al. 2011; Saaty 1980). The MCDM techniques, as useful tools, make options in discrete problems available to decision-makers. Especially, with the help of computers, those methods have become easier for the users, so they have found great acceptance in many areas of decision-making processes either in economy or in management. Among the MCDM techniques, the MAXMIN, MAXMAX, SAW, AHP, TOPSIS, SMART, ELECTRE are the most frequently used methods (Chen, Hwang 1992). Considering the importance of the issue of haulage in mines and the fact that there is little work on the selection of a haulage system in mines, in this paper, the AHP, TOPSIS, AHP-TOPSIS and AHP-VIKOR methods are used to rank and select the best haulage system for the Parvadeh Coal Mine. To achieve a general consensus over the ranking, the Borda and Copeland's average integrated technique is applied. The Expert Choice Software is also used to perform some of the calculations. 


\section{MULTI-CRITERIA DECISION MAKING METHODS}

\subsection{AHP METHOD}

The Analytic Hierarchy Process (AHP) method was developed by Thomas Saaty as a tool in the decision-making analysis at the beginning of the 1870s. It was designed to assist planners in resolving complex decision-making problems where a large number of planners participate, and a number of criteria exist in several specific time periods (Despodov, Peltechki 2011). Through the AHP, experts' judgments are used to measure the relative weights of certain criteria (Karahalios et al. 2011). To this end, initially, a pair-wise comparison matrix of criteria $(A)$ is established by using a relative importance scale, as introduced by Saaty (Saaty 1980). This 1-9 scale measures the intangibles in relative terms and is presented in Table 1.

Table 1. Scale of relative importance (Saaty 1980)

\begin{tabular}{|c|l|}
\hline Numerical assessment & \multicolumn{1}{|c|}{ Linguistic meaning } \\
\hline 1 & equal importance \\
\hline 3 & weak importance of one over another \\
\hline 5 & essential or strong importance \\
\hline 7 & demonstrated importance \\
\hline 9 & absolute importance \\
\hline $2,4,6,8$ & intermediate values between the two adjacent judgments \\
\hline
\end{tabular}

The pairwise comparison enables a decision-maker to evaluate the impact of each factor on the objective (Karahalios 2017). In an arbitrary random reciprocal matrix A, each criterion $a_{i j}(i, j=1,2, \ldots, n)$ is the relative importance of $i$-th elements compared to the $j$-th elements. In fact, it expresses that higher values of $a_{i j}$ indicate stronger preference of criteria $a_{i}$ over $a_{j}$. In the matrix, $a_{i j}=1$ when $i=j$ and $a_{j i}=\frac{1}{a_{i j}}$ (Akyuz et al. 2015).

$$
\mathbf{A}=\left[\begin{array}{cccc}
1 & a_{12} & \ldots & a_{1 n} \\
a_{21} & 1 & \ldots & a_{2 n} \\
\vdots & \vdots & \ddots & \vdots \\
a_{n 1} & a_{n 2} & \ldots & 1
\end{array}\right]
$$

Some technique, like the eigenvalue method, is used to calculate the relative weights of elements in each pairwise comparison matrix. The relative weights, $W$, of matrix $\mathbf{A}$ are obtained from: 


$$
\left(\mathbf{A}-\lambda_{\max } I\right) \times W=0,
$$

where $\lambda_{\max }$ is the biggest eigenvalue of matrix $\mathbf{A}$ and the unit matrix.

The consistency for pairwise comparisons in AHP is calculated by the consistency ratio $(C R)$, which measures the probability that the pairwise comparison matrix is filled in purely at random (Veisi et al. 2016). The $C I$ is the consistency index which can be obtained from Eq. (3), where $R I$ is the random index for matrix $\mathbf{A}$ and is shown in Table 2 (Saaty 1994).

$$
\begin{gathered}
C I=\frac{\lambda_{\max }-n}{n-1}, \\
R=\frac{C I}{R I} .
\end{gathered}
$$

Table 2. Random index values

\begin{tabular}{|c|c|c|c|c|c|c|c|c|c|c|}
\hline$N$ & 1 & 2 & 3 & 4 & 5 & 6 & 7 & 8 & 9 & 10 \\
\hline$R I$ & 0 & 0 & 0.58 & 0.90 & 1.12 & 1.24 & 1.32 & 1.41 & 1.45 & 1.49 \\
\hline
\end{tabular}

In the last step, the relative weights of the decision-making elements are aggregated to obtain an overall rating for the alternatives as follows:

$$
W_{i}^{s}=\sum_{j=1}^{m} W_{i j}^{s} W_{j}^{a}, \quad i=1,2, \ldots, m,
$$

where $W_{i}^{s}$ is the total weight of alternative $i, W_{i j}^{s}$ the weight of alternative $i$ associated to attribute $j, W_{j}^{a}$ the weight of attribute $j, m$ the number of attributes and $n$ the number of alternatives (Safari et al. 2010).

\subsection{TOPSIS METHOD}

TOPSIS (Technique for Order of Preference by Similarity to an Ideal Solution) method is presented in Chen and Hwang (1992) with reference to Hwang and Yoon (1995). TOPSIS is a multiple criteria method to identify solutions from a finite set of alternatives. The basic principle is that the chosen alternative should have the shortest distance from the positive ideal solution and the farthest distance from the negative ideal solution. The procedure of TOPSIS can be expressed in a series of steps (Elsayed et al. 2017):

1. Construct the decision matrix and determine the weight of the criteria;

2. Calculate the normalized decision matrix. The normalized value $n_{i j}$ is calculated as: 


$$
n_{i j}=\frac{x_{i j}}{\sqrt{\sum_{i=1}^{m} x_{i j}^{2}}}, \quad i=1,2, \ldots, m, j=1,2, \ldots, n
$$

3. Calculate the weighted normalized decision matrix. The weighted normalized value $v_{i j}$ is calculated as:

$$
v_{i j}=w_{j} n_{i j}, \quad i=1,2, \ldots, m, j=1,2, \ldots, n,
$$

where $w_{j}$ is the weight of the $i$-th attribute or criterion, and $\sum_{j=1}^{n} w_{j}=1$;

4. Determine the positive ideal and negative ideal solution:

$$
\begin{aligned}
& A^{+}=\left\{v_{1}^{+}, v_{2}^{+}, \ldots, v_{n}^{+}\right\}=\left\{\left(\max v_{i j} \mid i \in I\right),\left(\min v_{i j} \mid i \in J\right)\right\}, \\
& A^{-}=\left\{v_{1}^{-}, v_{2}^{-}, \ldots, v_{n}^{-}\right\}=\left\{\left(\min v_{i j} \mid i \in I\right),\left(\max v_{i j} \mid i \in J\right)\right\},
\end{aligned}
$$

where $I$ and $J$ are respectively associated with benefit and cost criteria;

5. Calculate the separation measures using the $n$-dimensional Euclidean distance. The separation of each alternative from the ideal solution is given as follows (Elsayed et al. 2017):

$$
d_{i+}=\sqrt{\left\{\sum_{j=1}^{n}\left(v_{i j}-v_{j}^{+}\right)^{2}\right\}} .
$$

Similarly, the separation from the negative ideal solution is given as:

$$
d_{i-}=\sqrt{\left\{\sum_{j=1}^{n}\left(v_{i j}-v_{j}^{-}\right)^{2}\right\}} ;
$$

6. Calculate the relative closeness to the ideal solution. The relative closeness of the alternative $A_{i}$ with respect to $A^{+}$is defined as:

$$
C L_{i+}=\frac{d_{i-}}{d_{i-}+d_{i+}}, \quad i=1,2, \ldots, m
$$

7. Rank the preference order. To rank the alternatives using this index, we can rank alternatives in a decreasing order. The basic principle of the TOPSIS method is that the chosen alternative should have the shortest distance from the positive ideal solution and the farthest distance from the negative ideal solution (Jahanshahloo et al. 2006). 


\subsection{VIKOR METHOD}

The VIKOR method is a type of MCDM or MCDA method. It was originally developed by Serafim Opricovic to solve decision-making problems with conflicting and non-commensurable (different units) criteria. According to this method, while assuming that a compromise is acceptable for the conflict resolution, the decisionmaker seeks for a solution which is closest to the ideal, and the alternatives are evaluated according to all the established criteria. The VIKOR ranks the alternatives and determines the solution named compromise, which is closest to the ideal (Opricovic, Tzeng 2004).

The compromise ranking algorithm VIKOR has the following steps:

1. Determine the best $f_{i}^{+}$and the worst $f_{i}^{-}$values of all criterion functions, $i=1$, $2,3, \ldots, n$ :

$$
\begin{aligned}
& f_{i}^{+}=\max f_{i j}, \quad f_{i}^{-}=\min f_{i j}, \\
& f_{i}^{+}=\min f_{i j}, f_{i}^{-}=\max f_{i j} ;
\end{aligned}
$$

2. Compute the values $S_{j}$ and $R_{j}, j=1,2,3, \ldots, \mathrm{J}$ by the Eq. (14).

$$
R_{j}=\max w_{j} \frac{f_{j}^{+}-f_{i j}}{f_{j}^{+}-f_{j}^{-}}, \quad S_{j}=\sum_{j=1}^{n} \frac{f_{j}^{+}-f_{i j}}{f_{j}^{+}-f_{j}^{-}},
$$

where $W_{i}$ are the weights of the criteria, expressing the DM's preference as the relative importance of the criteria;

3. Compute the values $Q_{j}, j=1,2,3, \ldots, J$ through the following relation:

$$
Q_{j}=\vartheta\left[\frac{S_{i}-S^{-}}{S^{+}-S^{-}}\right]+(1-\vartheta)=\left[\frac{R_{i}-R^{-}}{R^{+}-R^{-}}\right] ;
$$

4. Rank the alternatives while sorting the values $S, R$ and $Q$ in decreasing order (Tzimopoulos et al. 2013).

\section{AGGREGATION TECHNIQUES OF MCDM}

With various MCDM techniques, there is the possibility of different rankings for the same issue. In this case, it is possible to use aggregating techniques such as ranks mean, Borda, and Copland in order to assemble the different ranks to obtain the final value (Yoon, Hwang 1995; Tzeng, Huang 2011). 


\subsection{RANKS MEAN TECHNIQUE}

In this technique, the alternatives are prioritized based on the achieved arithmetic mean of the ranks from different MCDM methods. Obviously, the alternatives with the highest arithmetic mean will be preferred (Tajvidi et al. 2015)

\subsection{BORDA TECHNIQUE}

This technique is based on the majority rule, and the rank of each pair is compared with each other in different ranking ways. If the preferences of alternative $K$ over alternative $L$ is more than the preferences of alternative $L$ over alternative $K$, it means win $(M)$, and if the former is less than or equal to the latter, it means lost $(X)$. In this condition, the priority attribute for each alternative is considered as the summation of their win $\left(M_{s}\right)$ (Yoon, Hwang 1995; Tajvidi et al. 2015).

\subsection{COPLAND TECHNIQUE}

This technique can be considered as a correction of the previous techniques, since, in addition to $M_{s}$, the number of $X_{s}$ is also considered in prioritization. In other words, the score of each alternative in Copland Technique is calculated based on the difference of the number of wins from the number of defeats in accordance with the following equation (Tzeng, Huang 2011):

$$
T_{i}=\sum M_{i}-\sum X_{i}
$$

\section{CASE STUDY: PARVADEH COAL MINE}

The Tabas coal mine is located in a remote rugged desert environment, approximately $85 \mathrm{~km}$ south of Tabas town in the Southern Khorasan province in the east of Iran (Fig. 1). The Tabas region is a part of the central Iran's geological classification zones. The Tabas zone is divided into different sub-zones, namely Tabas (Parvadeh, Nayband) and Mazinu. The eastern Parvadeh coal deposit is divided by the Zenoughan fault, which divides the north and south blocks. According to the dip, depth and tectonic effects, the coal seams in the north block are generally accepted to be better than those in the south block (Sahebi et al. 2010).

In the Parvardeh Mine, three steep tunnels, one for ventilation and the other two for transportation and return ventilation have been excavated to perform the extraction operation. These tunnels have been drilled with a 30-degree-angle to the lower horizons, and then two horizons (penetration tunnels) were drilled in the coal layer. The 
two horizons have been connected in a distance of about $200 \mathrm{~m}$ off the work bed, forming a workshop. The length of each tunnel is $1430 \mathrm{~m}$.

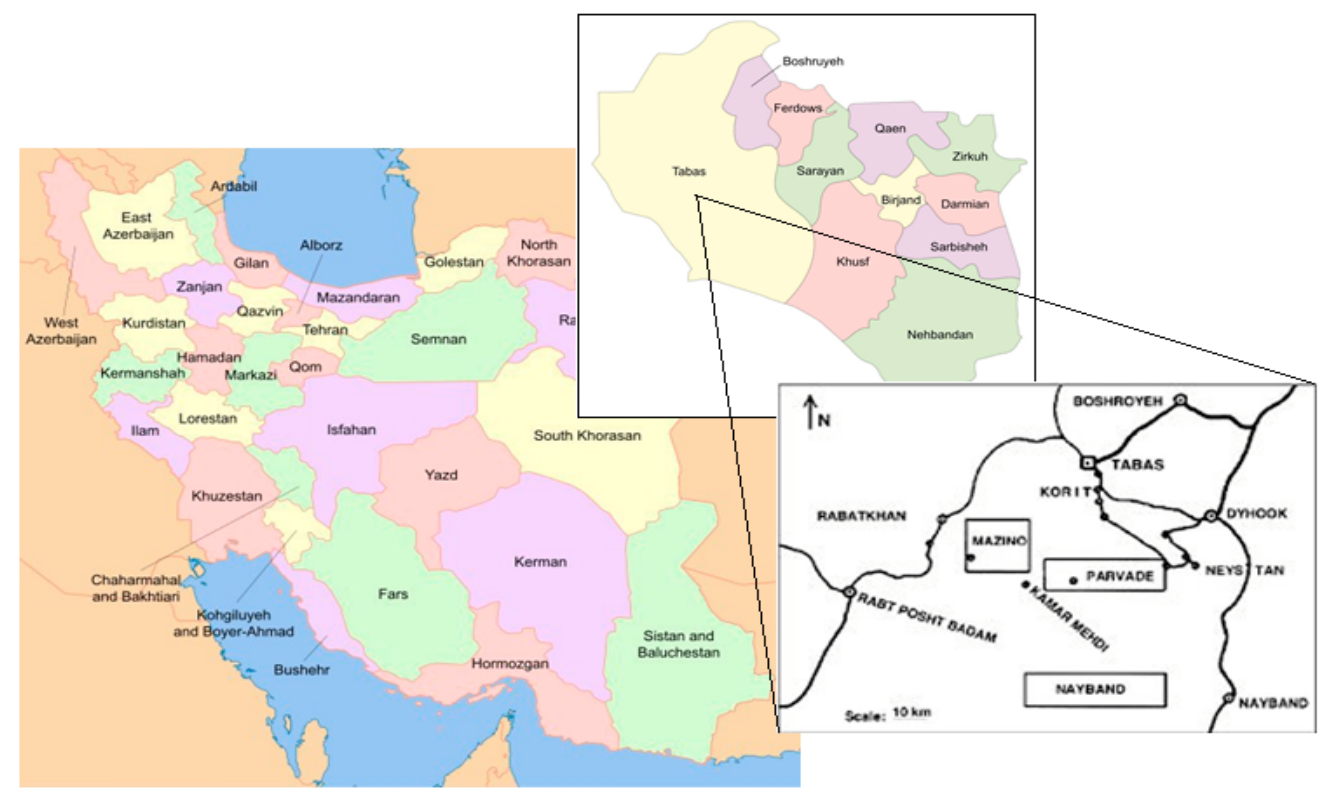

Fig. 1. Location of the Parvadeh Coal Mine

One of the underground coal extraction methods is the Longwall Mining. This is a highly productive process for coal extraction with a high recovery rate (Yetkin et al. 2016). The Longwall Mining method is used to extract coal in the Parvadeh Coal Mine. Several haulage tools and vehicles are used in mines for the Longwall method among which three conveyor systems, winch and wagons and locomotives and wagons have been suggested according to the system requirements for the haulage in the Parvadeh Coal Mine, and the best system should be chosen among the proposed systems by a multi-criteria decision method. These haulage systems are explained below.

\subsection{HAULAGE SYSTEM}

\subsubsection{CONVEYOR SYSTEM}

Belt conveyors have been used for mineral haulage below the mine ground. This system is used to move from a pillar and stall form to Longwall Mining systems in order to obtain more efficient haulage of materials. As the belt conveyor drive-unit power, width and tensile strength increased, the conveyors gradually started to displace main line underground locomotive systems, as the preferred means of material transportation over long distances. Conveyors are extensively used for man-riding and occasion- 
ally for material haulage. Developments in monitoring and control have enabled the whole networks of underground conveyors to be computer-operated from surface control rooms.

There are limiting factors affecting the use of belt conveyors; for example, a reasonably straight run is usually necessary, the maximum angle of inclination is normally 25 degrees ( 1 in 4) and the maximum lump size must be less than about half the width of the belt. Notwithstanding the above, the belt conveyor has a tremendous and expanding mineral transport potential. A conveyor belt may be defined as a number of load carrying members bonded together with polymeric compounds, and protected from mechanical or chemical damage by elastomeric covers. The load carrying members usually consist of either a number of plies of woven fabric, a single solid woven fabric, or a single layer of parallel, equidistant steel cables (Walker 2012).

\subsubsection{LOCOMOTIVE AND WAGON}

Locomotives were introduced for underground operation in coal mines in the early 1930s, but their use did not become widespread until after the 1939-1945 war. Although the conveyor cannot be outclassed for the underground bulk movement of materials, it lacks the flexibility of the locomotive with its ready potential to transport men, minerals or supplies, all with equal facility in both directions. If there is a need for a single-way transport of men, materials and supplies, a locomotive system must be seriously considered (Powell 1984). The principal types of mine locomotives include diesel, battery, trolley, battery/trolley, and to a very small degree, the flywheel form, together with compressed air powered. At least in principle, the flameproof diesel locomotive is fairly straight forward, consisting of an engine from which power is applied through a transmission system to the wheels. The battery locomotive has similar advantages of mobility like the diesel counterpart. Frames, buffer gear, braking equipment and, to a degree, wheels and axles are similar in construction to those employed on the diesel locomotive. This form of locomotive, like other ones, has its own pros and cons. The fundamental advantage of the battery locomotive is that it is clean, silent, relatively pollution-free in operation and reliable, and requires a low order of maintenance. Trolley locomotives resemble battery locomotives in that the arrangement of motors, wheels and axles, brakes and control gear is the same. The distinguishing feature of the trolley locomotive is that they carry some form of collector(s) to pick up their power supply from a live overhead conductor (Walker 2012).

Underground locomotives are principally used in two distinct areas including:

(a) Gathering duties, secondary haulage and shaft bottom work, and

(b) Main road haulage (Powell 1984).

The maximum longitudinal slope of rail transportation lines using the system of locomotives is $2 \%$ and the maximum permitted speed for freight locomotives is $12-18 \mathrm{~km} / \mathrm{h}$. 


\subsubsection{WINCH AND WAGON}

A mine winch refers to an electrical winch used in different kinds of mines. A winching machine can be set inner the mine or outer the mine. A mine winch is usually placed in coal mines and various metal mines. A winch is set in and out of a mine to carry and drag materials. For underground constructions and deep mining, winches and drives are essential for efficient and safe operations.

Compared with belt conveyors or locomotive transport, winch and wagon haulages are labor intensive. With good standards of track installation and maintenance, winch and wagon haulages can in many cases compete successfully with other more complex systems. Indeed, winch and wagon haulage systems can operate safely and economically in situations where other systems cannot, e.g. on steep gradients and in extremely wet conditions.

\subsection{EFFECTIVE CRITERIA}

The important criteria for the selection of a transport system at the Parvadeh Coal Mine, which were well thought out in this research, are summarized in Table 3.

Table 3. Random index values

\begin{tabular}{|l|l|}
\hline$C_{i}$ & \multicolumn{1}{|c|}{ Criteria for a haulage system selection } \\
\hline$C_{1}$ & Availability \\
\hline$C_{2}$ & Reliability (safety) \\
\hline$C_{3}$ & Repair and maintenance \\
\hline$C_{4}$ & The cost of energy and fuel \\
\hline$C_{5}$ & The cost of training operator and technician \\
\hline$C_{6}$ & Flexibility \\
\hline$C_{7}$ & Initial purchase price of the device \\
\hline$C_{8}$ & Useful life \\
\hline
\end{tabular}

Availability. The availability and utilization study is a known method to measure the performance of production equipment in manufacturing industries, which is also adapted for mining industry (Arputharaj 2015).

Reliability (safety). Reliability is a fundamental attribute for the safe operation of any modern technological system. Focusing on safety, a reliability analysis aims at the quantification of failure probability and the protective barriers of a system (Zio 2009).

Repair and maintenance. Repair and maintenance involves the incurred costs to bring back the assets to an earlier condition or to keep them operating at their present condition. For example, if a company truck is damaged, the cost of repairing the cost of damage is immediately debited to the repairs and maintenance expense. The routine 
maintenance costs such as the ones of engine tune-ups, oil change, radiator flushing, etc. are also debited to the repairs and maintenance expense.

In order to run the winch and wagon and the conveyor systems, the electrical energy is used. In the locomotive and wagon system, depending on the type of diesel, which is either electrical or compressed air locomotives, the type of consumed energy and the respective costs vary. However, since the diesel fuel cost is low, the use of diesel locomotives is a priority here. After comparing the three systems, i.e. winch and wagon, conveyor and locomotive wagons in terms of the consumed energy cost per each unit of carried coal, it was found out that the winch and wagon system costs less than the other two alternatives, and so it is more favorable according to this criterion.

The cost of energy and fuel. In order to run the winch and wagon and the conveyor systems, the electrical energy is used. In the locomotive and wagon system, depending on the type of diesel, electrical or compressed air locomotives, the type of consumed energy and the respective costs vary. However, since the diesel fuel cost is low, the use of diesel locomotives is a priority here. Upon comparing the three systems of winch and wagon, conveyor and locomotive wagons based on the cost of the consumed energy per each unit of carried coal, it was revealed that the winch and wagon system costs less than the other two alternatives, and so it is more favorable.

Costs of operator and technician training. It is a necessity to have skilled and knowledgeable operators who can work with each haulage system. Accordingly, a locomotive and wagon system requires a skilled operator to run and perform the transportation, as well as a specialized repair man to be maintained and repaired. On the other hand, for the conveyor system, there is no need for a permanent operator, and it requires only a person to run and stop it, which can be done by an unskilled worker too. Yet, for the repair of the conveyor, a specialist is needed while the maintenance and repair costs of which are very high. The winch and wagon system requires at least one permanent operator and constant control. Although the system can be simply repaired and requires no specialist, it needs frequent checks to become assured of the tensile strength and resistance of the cable.

Flexibility. Flexibility is used as an attribute of various types of systems. Flexibility has been defined differently in many fields of engineering, architecture, biology, economics, etc. In the context of engineering design, one can define flexibility as the ability of a system to respond to potential internal or external changes affecting its value delivery, in a timely and cost-effective manner. Thus, flexibility in an engineering system is the ease with which a system can respond to uncertainty while sustaining or increasing its value delivery. Uncertainty is a key element in the definition of flexibility. Uncertainty can create both risks and opportunities in a system, and it is with the existence of uncertainty that flexibility finds value (Sethi, Sethi 1990).

Initial purchase price of the device. One of the objectives of searching for the proper transportation system for the Parvardeh Coal Mine of Tabas is to minimize 
the total costs. Since the initial cost of purchasing freight machineries is usually high and includes a large part of the total cost, it must be considered for the selection of the freight system. Comparing the three winch and wagon systems, conveyor and locomotive wagons, based on the initial cost or the initial purchase price, we realize that the initial cost for the purchase and running of the winch and wagon system is lower than the other two options, and the conveyor system has the highest initial cost.

Useful life. Useful life is a period during which an asset or property is expected to be usable for the purpose it was designed. It may or may not correspond with the item's actual physical life or economic life.

Upon the selection of the $A_{1}, A_{2}$ and $A_{3}$ and the effective criteria, the importance and status of each of them was qualitatively assessed by specialists according to the criteria. The overall opinion of them regarding such an assessment based on 8 criteria as well as the significance of the criteria are respectively shown in Tables 4 and 5 .

Table 4. The scale of alternative ratings for qualitative criterion in the case of classical TOPSIS method

\begin{tabular}{|c|c|c|c|c|c|c|c|c|}
\hline & $C_{1}(+)$ & $C_{2}(+)$ & $C_{3}(-)$ & $C_{4}(-)$ & $C_{5}(-)$ & $C_{6}(+)$ & $C_{7}(-)$ & $C_{8}(+)$ \\
\hline$A_{1}$ & $\mathrm{G}$ & $\mathrm{MG}$ & $\mathrm{G}$ & $\mathrm{F}$ & $\mathrm{F}$ & $\mathrm{F}$ & $\mathrm{MP}$ & $\mathrm{MG}$ \\
\hline$A_{2}$ & $\mathrm{MG}$ & $\mathrm{MP}$ & $\mathrm{F}$ & $\mathrm{MG}$ & $\mathrm{F}$ & $\mathrm{MG}$ & $\mathrm{MG}$ & $\mathrm{F}$ \\
\hline$A_{3}$ & $\mathrm{~F}$ & $\mathrm{~F}$ & $\mathrm{MP}$ & $\mathrm{MP}$ & $\mathrm{MG}$ & $\mathrm{F}$ & $\mathrm{F}$ & $\mathrm{F}$ \\
\hline
\end{tabular}

\section{NUMERICAL EXAMPLE: THE SELECTION OF HAULAGE SYSTEM FOR PARVADEH COAL MINE BY USING A HYBRID OF MULTI-CRITERIA DECISION MAKING METHODS}

The selection of a haulage system for the Parvadeh Coal Mine was carried out using a hybrid of the AHP, TOPSIS, AHP-TOPSIS and AHP-VIKOR methods as follows.

\subsection{HAULAGE SYSTEM SELECTION BY USING THE AHP METHOD}

The first step in the AHP procedure is to decompose the decision problem into a hierarchy consisting of the most important elements of the decision making problem. The hierarchy of a transport system selection for the Parvadeh Coal Mine is illustrated in Fig. 2. The pairwise comparison matrix established using a nine-point scale is given in Table 5. Then, the final weight of the criteria is calculated using the Expert Choice Software and is given in Table 6 (Ishizaka 2009). To determine the priority, the concept of normalization has been used. The value of each option is yielded through the 
Haulage system selection for Parvadeh Coal Mine using multi-criteria decision making methods 81

priority value of the option based on Criterion i multiplied by the weight of the criterion as calculated in Eq. (4) and stated in Table 7.

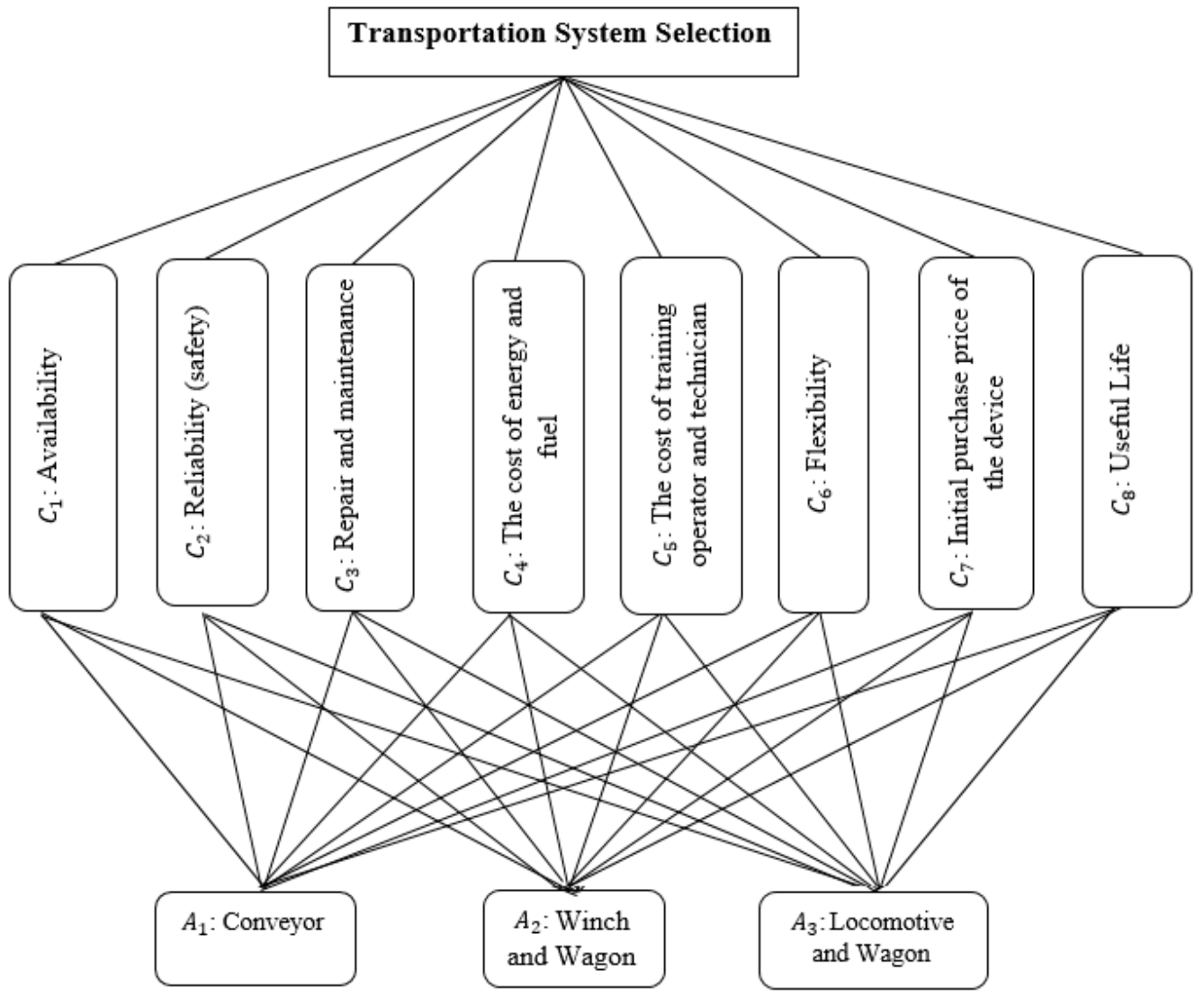

Fig. 2. Hierarchical structure of the decision problem

Table 5. Pairwise comparison matrix

\begin{tabular}{|c|c|c|c|c|c|c|c|c|}
\hline & $C_{1}$ & $C_{2}$ & $C_{3}$ & $C_{4}$ & $C_{5}$ & $C_{6}$ & $C_{7}$ & $C_{8}$ \\
\hline$C_{1}$ & 1 & $1 / 5$ & $1 / 5$ & 1 & 3 & 1 & 1 & 1 \\
\hline$C_{2}$ & 5 & 1 & $1 / 3$ & 5 & 5 & 1 & 3 & 5 \\
\hline$C_{3}$ & 5 & 1 & 1 & 5 & 5 & 3 & 1 & $1 / 3$ \\
\hline$C_{4}$ & 1 & 0.2 & 0.2 & 1 & 3 & $1 / 3$ & $1 / 3$ & $1 / 3$ \\
\hline$C_{5}$ & $1 / 3$ & 0.2 & 0.2 & $1 / 3$ & 1 & $1 / 3$ & $1 / 3$ & $1 / 3$ \\
\hline$C_{6}$ & 1 & 1 & $1 / 3$ & 3 & 3 & 1 & 3 & 1 \\
\hline$C_{7}$ & 1 & $1 / 3$ & 1 & 3 & 3 & $1 / 3$ & 1 & $1 / 3$ \\
\hline$C_{8}$ & 1 & 0.2 & 3 & 3 & 3 & 1 & 3 & 1 \\
\hline
\end{tabular}


Table 6. Final weight of criteria based on AHP method

\begin{tabular}{|c|c|c|c|c|c|c|c|c|}
\hline & $C_{1}$ & $C_{2}$ & $C_{3}$ & $C_{4}$ & $C_{5}$ & $C_{6}$ & $C_{7}$ & $C_{8}$ \\
\hline$W_{i}$ & 0.072 & 0.241 & 0.234 & 0.046 & 0.031 & 0.123 & 0.084 & 0.169 \\
\hline
\end{tabular}

Table 7. Total weight of each alternative

\begin{tabular}{|c|c|}
\hline$A_{i}$ & Total weight \\
\hline$A_{1}$ & 0.0536 \\
\hline$A_{2}$ & 0.0273 \\
\hline$A_{3}$ & 0.0190 \\
\hline
\end{tabular}

According to the calculations, the ranking of the transport system in the order of priority is given in Table 8 .

Table 8. The ranking of the alternatives by AHP

\begin{tabular}{|c|c|l|}
\hline Rank & $A_{i}$ & \multicolumn{1}{c|}{ Haulage System } \\
\hline 1 & $A_{1}$ & Conveyor System \\
\hline 2 & $A_{2}$ & Winch and Wagon \\
\hline 3 & $A_{3}$ & Locomotive and Wagon \\
\hline
\end{tabular}

\subsection{HAULAGE SYSTEM SELECTION BY USING THE TOPSIS METHOD}

Since, in the questionnaire forms, the options are qualitatively evaluated by experts based on each positive and negative criterion, the preferred option is qualitatively determined (Table 4). In order to conduct the calculations using the TOPSIS, and for the selection of an appropriate option, the qualitative scores must be turned first into quantitative ones by Table 9 (Table 10) and then the other stages of the method could be followed.

Table 9. The scale of alternative ratings for qualitative criterion

\begin{tabular}{|l|c|c|}
\hline \multirow{2}{*}{\multicolumn{1}{|c|}{ Rating }} & \multicolumn{2}{|c|}{ Scale } \\
\cline { 2 - 3 } & Positive criterion & Negative criterion \\
\hline Poor (P) & 1 & 9 \\
\hline Medium poor (MP) & 3 & 7 \\
\hline Fair (F) & 5 & 5 \\
\hline Medium good (MG) & 7 & 3 \\
\hline Good (G) & 9 & 1 \\
\hline
\end{tabular}


Haulage system selection for Parvadeh Coal Mine using multi-criteria decision making methods 83

Table 10. Decision matrix

\begin{tabular}{|c|c|c|c|c|c|c|c|c|}
\hline & $C_{1}(+)$ & $C_{2}(+)$ & $C_{3}(-)$ & $C_{4}(-)$ & $C_{5}(-)$ & $C_{6}(+)$ & $C_{7}(-)$ & $C_{8}(+)$ \\
\hline$A_{1}$ & 9 & 7 & 1 & 5 & 5 & 5 & 7 & 7 \\
\hline$A_{2}$ & 7 & 3 & 5 & 3 & 5 & 7 & 3 & 5 \\
\hline$A_{3}$ & 5 & 5 & 7 & 7 & 3 & 5 & 5 & 5 \\
\hline
\end{tabular}

In this procedure, using Eq. (6), the normalized weighted decision matrix (Table 13) is respectively composed according to the normalized decision matrix (Table 11) and the criteria weight matrix (Table 12).

The criteria weight matrix was obtained as Eqs. (17)-(20) (Mavi et al. 2016).

$$
\begin{gathered}
p_{i j}=\frac{x_{i j}}{\sum x_{i j}}, \quad i=1,2, \ldots, m, j=1,2, \ldots, n, \\
E_{j}=-\frac{1}{\operatorname{Ln} 3} \sum_{i=1}^{n} p_{i j} L_{n} p_{i j}, \\
D_{j}=1-E_{j}, \\
W_{j}=\frac{D_{j}}{\sum D_{j}} .
\end{gathered}
$$

Table 11. The normalized decision matrix in TOPSIS method

\begin{tabular}{|c|c|c|c|c|c|c|c|c|}
\hline & $C_{1}(+)$ & $C_{2}(+)$ & $C_{3}(-)$ & $C_{4}(-)$ & $C_{5}(-)$ & $C_{6}(+)$ & $C_{7}(-)$ & $C_{8}(+)$ \\
\hline$A_{1}$ & 0.0581 & 0.0843 & 0.0133 & 0.0602 & 0.0847 & 0.0505 & 0.0843 & 0.0707 \\
\hline$A_{2}$ & 0.0452 & 0.0361 & 0.0667 & 0.0361 & 0.0847 & 0.0707 & 0.0361 & 0.0505 \\
\hline$A_{3}$ & 0.0323 & 0.0602 & 0.0933 & 0.0843 & 0.0508 & 0.0505 & 0.0602 & 0.0505 \\
\hline
\end{tabular}

Table 12. The criteria weight matrix

\begin{tabular}{|c|c|c|c|c|c|c|c|c|}
\hline & $C_{1}(+)$ & $C_{2}(+)$ & $C_{3}(-)$ & $C_{4}(-)$ & $C_{5}(-)$ & $C_{6}(+)$ & $C_{7}(-)$ & $C_{8}(+)$ \\
\hline$E_{i}$ & 0.975 & 0.950 & 0.818 & 0.950 & 0.977 & 0.988 & 0.950 & 0.988 \\
\hline$D_{i}$ & 0.025 & 0.050 & 0.182 & 0.050 & 0.023 & 0.012 & 0.050 & 0.012 \\
\hline$W_{i}$ & 0.062 & 0.123 & 0.451 & 0.123 & 0.057 & 0.030 & 0.123 & 0.030 \\
\hline
\end{tabular}

Table 13. The normalized weighted decision matrix

\begin{tabular}{|c|c|c|c|c|c|c|c|c|}
\hline & $C_{1}(+)$ & $C_{2}(+)$ & $C_{3}(-)$ & $C_{4}(-)$ & $C_{5}(-)$ & $C_{6}(+)$ & $C_{7}(-)$ & $C_{8}(+)$ \\
\hline$A_{1}$ & 0,0036 & 0.0104 & 0.0060 & 0.074 & 0.0048 & 0.0015 & 0.0104 & 0.0021 \\
\hline$A_{2}$ & 0.0028 & 0.0045 & 0.0301 & 0.0045 & 0.0048 & 0.0021 & 0.0045 & 0.0015 \\
\hline$A_{3}$ & 0.0020 & 0.0074 & 0.0421 & 0.104 & 0.0029 & 0.0015 & 0.0074 & 0.0015 \\
\hline
\end{tabular}


The positive and negative ideal solutions were calculated using Eqs. 7 and 8 as follows:

$$
\begin{aligned}
& A^{+}=\{0.0042,0.0203,0.0031,0.0017,0.0016,0.0087,0.0030,0.0119, \\
& A^{-}=\{0.0023,0.0087,0.0218,0.0039,0.0026,0.0062,0.0071,0.0085 .
\end{aligned}
$$

The separation of each alternative from the ideal solution is given in Tables 14 and 15. The relative closeness to the ideal solution is also calculated using Eqs. (9)-(11). The results of the calculations are given in Table 16.

Table 14. The separation of positive ideal solution

\begin{tabular}{|c|c|}
\hline$d_{i+}$ & Calculated values \\
\hline$d_{1+}$ & 0.0069 \\
\hline$d_{2+}$ & 0.0249 \\
\hline$d_{3+}$ & 0.0368 \\
\hline
\end{tabular}

Table 15. The separation of negative ideal solution

\begin{tabular}{|l|c|}
\hline$d_{i-}$ & Calculated values \\
\hline$d_{1-}$ & 0.0367 \\
\hline$d_{2-}$ & 0.0147 \\
\hline$d_{3-}$ & 0.0046 \\
\hline
\end{tabular}

Table 16. The closeness to the ideal solution

\begin{tabular}{|c|c|}
\hline$C L_{i}$ & Calculated values \\
\hline$C L_{1}$ & 0.84 \\
\hline$C L_{2}$ & 0.37 \\
\hline$C L_{3}$ & 0.11 \\
\hline
\end{tabular}

Given the performed calculations and the closeness of the number to 1 , the rankings of the alternatives are stated in the order of preference in Table 17 for $A_{1}$, $A_{2}$ and $A_{3}$.

Table 17. The ranking of the alternatives by TOPSIS

\begin{tabular}{|c|c|l|}
\hline Rank & $A_{i}$ & \multicolumn{1}{|c|}{ Haulage System } \\
\hline 1 & $A_{1}$ & conveyor system \\
\hline 2 & $A_{2}$ & winch and wagon \\
\hline 3 & $A_{3}$ & locomotive and wagon \\
\hline
\end{tabular}




\subsection{HAULAGE SYSTEM SELECTION \\ BY USING THE AHP-TOPSIS METHOD}

In this method, the weight of the criteria is calculated by the AHP method (Table 6). In the next step, the normalized weighted decision matrix (Table 18) is composed according to Tables 6 and 11 .

Table 18. The normalized weighted decision matrix

\begin{tabular}{|c|c|c|c|c|c|c|c|c|}
\hline & $C_{1}(+)$ & $C_{2}(+)$ & $C_{3}(-)$ & $C_{4}(-)$ & $C_{5}(-)$ & $C_{6}(+)$ & $C_{7}(-)$ & $C_{8}(+)$ \\
\hline$A_{1}$ & 0.0042 & 0.0203 & 0.0031 & 0.0028 & 0.0026 & 0.0062 & 0.0071 & 0.0119 \\
\hline$A_{2}$ & 0.0033 & 0.0087 & 0.0156 & 0.0017 & 0.0026 & 0.0087 & 0.0030 & 0.0085 \\
\hline$A_{3}$ & 0.0023 & 0.0145 & 0.0218 & 0.0039 & 0.0016 & 0.0062 & 0.0051 & 0.0085 \\
\hline
\end{tabular}

The positive and negative ideal solutions were calculated using Eqs. (7) and (8) as follows:

$$
\begin{aligned}
& A^{+}=\{0.0042,0.0203,0.0031,0.0017,0.0016,0.0087,0.0030,0.0119, \\
& A^{-}=\{0.0023,0.0087,0.0218,0.0039,0.0026,0.0062,0.0071,0.0085 .
\end{aligned}
$$

The separation of each alternative from the ideal solution is given in Tables 19 and 20 . The relative closeness to the ideal solution is also calculated using Eqs. (9)-(11). The results of the calculations are given in Tab. 21 .

Table 19. The separation of the positive ideal solution

\begin{tabular}{|c|c|}
\hline$d_{i+}$ & Calculated values \\
\hline$d_{1+}$ & 0.0050 \\
\hline$d_{2+}$ & 0.0174 \\
\hline$d_{3+}$ & 0.0204 \\
\hline
\end{tabular}

Table 20. The separation of negative ideal solution

\begin{tabular}{|l|c|}
\hline$d_{i-}$ & Calculated values \\
\hline$d_{1-}$ & 0.0224 \\
\hline$d_{2-}$ & 0.0082 \\
\hline$d_{3-}$ & 0.0062 \\
\hline
\end{tabular}


Table 21. The relative closeness to the ideal solution

\begin{tabular}{|c|c|}
\hline$C L_{i}$ & Calculated values \\
\hline$C L_{1}$ & 0.82 \\
\hline$C L_{2}$ & 0.32 \\
\hline$C L_{3}$ & 0.23 \\
\hline
\end{tabular}

According to the calculations, the rankings of the options are in the order of $A_{1}, A_{2}$ and $A_{3}$ as shown in Table 22.

Table 22. The ranking of the alternatives by AHP-TOPSIS

\begin{tabular}{|c|c|l|}
\hline Rank & $A_{i}$ & \multicolumn{1}{c|}{ Haulage system } \\
\hline 1 & $A_{1}$ & conveyor system \\
\hline 2 & $A_{2}$ & locomotive and wagon \\
\hline 3 & $A_{3}$ & winch and wagon \\
\hline
\end{tabular}

\subsection{HAULAGE SYSTEM SELECTION} BY USING THE AHP-VIKOR METHOD

In this method, the final weight of the options is calculated using the AHP method (Table 6). In the next step, according to the normalized decision matrix (Table 11), the best and worst amounts are calculated for each given criterion from among the existent values. Table 23 shows the usefulness and regret indexes for each alternative using Eq. (14). The amounts of the VIKOR index, $Q_{i}$, can finally be obtained through Eq. (15).

Table 23. $S_{i}$ and $R_{i}$ and $Q_{i}$ for transport system

\begin{tabular}{|c|c|c|c|}
\hline & $S_{i}$ & $R_{i}$ & $Q_{i}$ \\
\hline$A_{1}$ & 0.261 & 0.123 & 0 \\
\hline$A_{2}$ & 0.596 & 0.241 & 0.766 \\
\hline$A_{3}$ & 0.855 & 0.241 & 0.980 \\
\hline
\end{tabular}

According to Table 23:

$$
\begin{aligned}
s^{-} & =\min s_{i}=0.261, \\
s^{-} & =\max s_{i}=0.855, \\
R^{+} & =\max R_{i}=0.241, \\
R^{-} & =\min R_{i}=0.123 .
\end{aligned}
$$


According to the VIKOR method, the best option shall be the one which is also determined as best in all the three other groups in Table 23. Therefore, given the usefulness and regret indexes for each option and the VIKOR index, the ranking of the options is determined as shown in Table 24.

Table 24. The ranking of the alternatives by AHP-VIKOR

\begin{tabular}{|c|c|l|}
\hline Rank & $A_{i}$ & \multicolumn{1}{c|}{ Haulage system } \\
\hline 1 & $A_{1}$ & conveyor system \\
\hline 2 & $A_{2}$ & winch and wagon \\
\hline 3 & $A_{3}$ & locomotive and wagon \\
\hline
\end{tabular}

\subsection{AGGREGATE RANKING ALTERNATIVES}

The rankings of some alternatives are different in the three desired methods. In fact, in order to aggregate the obtained ranks, the ranks mean, Borda and Copland techniques were applied, the results of which are presented in the last three columns of Table 25.

Table 25. The ranking of the alternatives based on each ranking methods

\begin{tabular}{|c|l|c|c|c|}
\hline Alternatives & \multicolumn{1}{|c|}{ Haulage system } & Mean technique & Borda technique & Copland technique \\
\hline$A_{1}$ & conveyor system & 1 & 1 & 1 \\
\hline$A_{2}$ & winch and wagon & 2.25 & 2 & 2 \\
\hline$A_{3}$ & locomotive and wagon & 2.75 & 3 & 3 \\
\hline
\end{tabular}

After obtaining the loading vehicles ranking using all the Mean, Borda and Copland techniques, the results of the methods are coalesced so that a single ranking can be obtained for the loading vehicles, which is called the coalescence technique. In order to coalesce the three abovementioned methods, the average amount for each vehicle is calculated, the results of which is shown in Table 26.

Table 26. Ranking of alternatives using the coalesce technique

\begin{tabular}{|c|l|c|}
\hline Alternatives & \multicolumn{1}{|c|}{ Haulage system } & Coalesced ranking \\
\hline$A_{1}$ & conveyor system & 1 \\
\hline$A_{2}$ & winch and wagon & 2.083 \\
\hline$A_{3}$ & locomotive and wagon & 2.916 \\
\hline
\end{tabular}

Given the coalesce result, the final rankings of the alternatives are in the order of $A_{1}, A_{2}$, and $A_{3}$ as shown in Table 27. 
Table 27. Ranking of haulage systems results

\begin{tabular}{|c|c|l|}
\hline Rank & $A_{i}$ & \multicolumn{1}{|c|}{ Ranking of haulage system } \\
\hline 1 & $A_{1}$ & conveyor system \\
\hline 2 & $A_{2}$ & winch and wagon \\
\hline 3 & $A_{3}$ & locomotive and wagon \\
\hline
\end{tabular}

\section{CONCLUSION}

The selection of the haulage system involves an interaction of several subjective factors or criteria. Decisions are often complicated, and many even embody contradiction. One of the key parts of any project, especially mining projects, is the loading equipment selection and design. Since many parameters and criteria influence the loading equipment selection, the decision-making in this field is a complicated process. In this paper, loading systems, conveyors, winch and wagons, locomotives and wagons are investigated. Then, by using this method, a suitable loading system for the Parvadeh coal mine is selected, based on nine proposed criteria. This paper identifies the application of the AHP, TOPSIS, AHP-TOPSIS and AHP-VIKOR methods in the process of selecting during the planning phase of a transportation system in the Parvadeh Coal Mine. To achieve a general consensus of the obtained rankings, the Borda and Copeland's average integrated technique is applied. The Expert Choice Software is also used to conduct some calculations. Given the fact that the results were not consistent with each other in some cases after using the above methods, an integration technique was used. After integrating the results of the ranking methods, the conveyor transport system was eventually introduced as the best option.

\section{REFERENCES}

AGHAJANI A., OSANLOO M., October 2007, Application of AHP-TOPSIS method for loadinghaulage equipment selection in open pit mines, [in:] XXVII International Mining Convention, Mexico, pp. 12-16.

AKYUZ E., KARAHALIOS H., CELIK M., 2015, Assessment of the maritime labour convention compliance using balanced scorecard and analytic hierarchy process approach, Maritime Policy and Management, 42(2), pp. 145-162.

BASÇETIN A., 2004, An application of the analytic hierarchy process in equipment selection at Orhaneli open pit coal mine, Mining Technology, 113(3), pp. 192-199.

CHEN S.J., HWANG C.L., 1992, Fuzzy multiple attribute decision making methods, [in:] Fuzzy multiple attribute decision making, Springer, Berlin, Heidelberg, pp. 289-486.

DESPODOV Z., MITIĆ S., PELTEČKI D., 2011, Application of the AHP method for selection of a transportation system in mine planning, Podzemni radovi, (19), pp. 93-99.

ELSAYED E.A., SHAIK DAWOOD A.K., KARTHIKEYAN R., 2017, Evaluating Alternatives through the Application of Topsis Method with Entropy Weight, International Journal of Engineering Trends and Technology (IJETT), Vol. 46(2). 
ISHIZAKA A., LABIB A., 2009, Analytic hierarchy process and expert choice: Benefits and limitations, Or Insight, 22(4), pp. 201-220.

JAHANSHAHLOO G.R., LOTFI F.H., IZADIKHAH M., 2006, Extension of the TOPSIS method for decision-making problems with fuzzy data, Applied Mathematics and Computation, 181(2), pp. 1544-1551.

KARAHALIOS H., 2017, The application of the AHP-TOPSIS for evaluating ballast water treatment systems by ship operators, Transportation Research Part D: Transport and Environment, 52, pp. 172-184.

KARAHALIOS H., YANG Z.L., WILLIAMS V., WANG J., 2011, A proposed System of Hierarchical Scorecards to assess the implementation of maritime regulations, Safety Science, 49(3), pp. 450-462.

MATSUI K., 2001, Underdround Mining Transportation System, Civil Engineering.

MAVI R.K., GOH M., MAVI N.K., 2016, Supplier selection with Shannon entropy and fuzzy TOPSIS in the context of supply chain risk management, Procedia-Social and Behavioral Sciences, 235, pp. 216-225.

MIZRAK ÖZFIRAT P., ÖZFIRAT M.K., MALLI T., 2017, Selection of coal transportation mode from the open pit mine to the thermic power plant using Fuzzy Analytic Hierarchy Process, Transport, pp. 1-8.

OPRICOVIC S., TZENG G.H., 2004, Compromise solution by MCDM methods: A comparative analysis of VIKOR and TOPSIS, European Journal of Operational Research, 156(2), pp. 445-455.

POWELL F., MORETON G., 1984, An evaluation of brake block materials for underground locomotives. International Conference on Tribology in Mineral Extraction, Paper C349/84 - Institution of Mechanical Engineers.

SAATY T.L., 1980, The analytic hierarchy process: planning. Priority Setting. Resource Allocation, MacGraw-Hill, New York International Book Company.

SAATY T.L., 1994, How to make a decision: the analytic hierarchy process, Interfaces, 24(6), pp. 19-43.

SAFARI M., ATAEI M., KHALOKAKAIE R., KARAMOZIAN M., 2010, Mineral processing plant location using the analytic hierarchy process - a case study: the Sangan iron ore mine (phase 1), Mining Science and Technology (China), 20(5), pp. 691-695.

SAHEBI A., JALALIFAR H., EBRAHIMI M., ABDOLREZAEE A., 2010, Stability analysis of Tabas coal mine roadway using empirical and numerical methods.

TAJVIDI ASR E., HAYATY M., RAFIEE R., ATAIE M., JALALI S.E., 2015, Selection of Optimum Tunnel Support System Using Aggregated Ranking of SAW, TOPSIS and LA Methods, International Journal of Applied Operational Research - An Open Access Journal, 5(4), pp. 49-63.

TZENG G.H., HUANG J.J., 2011, Multiple attribute decision making: methods and applications, CRC Press.

TZIMOPOULOS C., ZORMPA D., EVANGELIDES C., 2013, Multi Criteria Decision Making Using VIKOR Method. Proceedings of the 13th International Conference on Environmental Science and Technology.

Underground locomotive haulage Mines Topic Report, 1991, Available free from HM Inspectorate of Mines, St Anne's House, Stanley Precinct, Bootle L20 3RA.

VEISI H., LIAGHATI H., ALIPOUR A., 2016, Developing an ethics-based approach to indicators of sustainable agriculture using analytic hierarchy process (AHP), Ecological Indicators, 60, pp. 644-654.

WALKER S.C., 2012, Mine winding and transport, Elsevier.

YETKIN M.E., SIMSIR F., OZFIRAT M.K., OZFIRAT P.M., YENICE H., 2016, A fuzzy approach to selecting roof supports in longwall mining, South African Journal of Industrial Engineering, 27(1), pp. $162-177$.

YOON K.P., HWANG C.L., 1995, Multiple attribute decision making: an introduction, Vol. 104, Sage publications. 